\title{
ULASAN TERHADAP KARYA TULIS EDI SUJOKO
}

\author{
Angel Christie Pakasi
}

Email: apakasi28@gmail.com

\begin{abstract}
Abstrak:
Ulasan ini membahas tentang sembilan artikel jurnal, prosiding, dan buku karya Edi Sujoko. Penulis melakukan analisis beberapa sumber pustaka yang terkait dengan topik bahasan. Dari hasil analisis beberapa sumber pustaka, Strategi Peningkatan Mutu Sekolah Berdasarkan Analisis SWOT di Sekolah Menengah Pertama dilakukan dengan adanya kerja sama guru-guru, staf dan peserta didik yang baik untuk mewujudkan kemajuan dalam peningkatan mutu sekolah menjadi sekolah yang terpercaya serta meningkatkan layanan kepuasan mahasiswa STT Simpson dan meningkatkan profesionalisme para pendidik dengan mengimplementasikan Pendidikan Agama Kristen pada konteks Gereja dan Sekolah. Dari ulasan yang penulis lakukan, karya tulis yang dihasilkan oleh Edi Sujoko pada tahun 2013 hingga 2019 relevan dengan bidang minat yang ditekuninya. Grafik publikasi dalam tiga tahun menunjukkan adanya peningkatan hasil karya ilmiah.

Kata Kunci: Pembelajaran, Mutu Ki Hajar Dewantara's, Pelayanan Anak, Profesionalisme, Pendidik, Mama Mela Menyanyi.
\end{abstract}

\section{PENDAHULUAN}

Sujoko menjelaskan bahwa persaingan antar Sekolah Menengah Pertama tidak dapat dihindarkan.[1] Tiap sekolah harus memiliki strategi tersendiri untuk bersaing. Karena hal ini sudah menjadi tuntutan yang harus dilakukan untuk memperbaiki mutu dan meningkatkan mutu pendidikan pada jenjang sekolah menengah pertama. Darmawan dan Sujoko menjelaskan bahwa pengaruh terhadap tingkat kepuasaan mahasiswa STT Simpson, secara kontinyu dari kelima hal penting untuk melihat pengaruh positif terhadap tingkat kepuasaan mahasiswa.[2] Nuh, Darmawan dan Sujoko menjelaskan bahwa mengimplementasikan Pendidikan Agama Kristen pada konteks Gereja adalah proses pengajaaran dan pembelajaran yang akan berpusat pada Alkitab dan Kristus.[3] Pendidikan Kirsten juga berperan dalam mengarahkan seseorang menuju pemahaman dan kedewasaan dalam Kristus. Oleh sebab itu, dalam kajian ini, seorang dosen dituntut untuk menghasilkan karya tulis baik ilmiah maupun 
non ilmiah. Dalam kajian ini, penulis mencermati hasil karya dari dosen untuk melihat progress penulisan karya ilmiahnya. Dalam ulasan ini juga, penulis mengulas karya ilmiah dosen yaitu Edi Sujoko.

Edi sujoko adalah seorang dosen yang mengajar di Sekolah Tinggi Teologi Simpson, Ungaran Timur, Kab Semarang, Jawa Tengah (sttsimpson.ac.id). Edi Sujoko mengajar dalam bidang Komunikasi, Strategi Pembelajaran, Studi Kebijakan, Mpmbs, Bahasa Inggris. Sudah menghasilkan 9 (Sembilan) Artikel Jurnal dari tahun 2013-2019 dan sudah diterbitkan. Dari ke sembilan artikel jurnal tersebut perlu diberikan ulasan supaya pembaca dapat memahami maksud dari semua isi jurnal tanpa perlu membaca seluruh isi jurnal aslinya.

\section{METODE}

Ulasan ini menggunakan pendekatan analisis literatur yang berkaitan dengan pendidikan baik pendididkan yang dilakukan dengan menggunakan Strategi Peningkatan Mutu Sekolah Berdasarkan Analisis Swot dan Strategi ini dilakukan pada Sekolah Menengah Pertama dan Pada Mahasiswa STT Simpson untuk melihat tingkat kepuasaannya terhadap suatu layanan pendididkan khususnya pada pendidikan agama kristen berdasarkan analisis swot. Tidak terlepas dari itu saja adanya peran dalam mengimpmentasikan Pendidikan Agama Kristen pada konteks Gereja untuk membahwa setiap orang yang dibina maupun dididik untuk mengenal Kristus. Serta Merevisi Taksonomi Pembelajaran Benyamin S.Bloom. dan memberikan pemahaman dari penjelasan tentang mama mela menyanyi untuk meningkatkan aktivitas dan hasil dari kegaiatan belajar. Penulis melakukan analisis terhadap artikel jurnal yang ditulis oleh Edi sujoko mulai tahun 2013-2019. Dalam bagian ini penulis memaparkan apakah dosen menghasilkan karya tulis sesuai bidangnya dan mekakukan usaha mengembangkan diri dalam karya tulis ilmiah atau fiksi/popular, serta perlunya dilakukan ulasan terhadap karya ilmiah tersebut. Sehingga dikumpulkan data-data yang berkaitan dengan sumber yang sudah diulas dan dihasilkan suatu simpulan sesuai dengan artikel jurnal yang terkait. 


\section{KARYA TULIS}

Karya Ilmiah

Karya pertama Sujoko di tahun 2013 membahas tentang Revisi Taksonomi Pembelajaran Benyamin S. Bloom. Darmawan, Sujoko 2013 Mengungkapkan perubahan Taksonomi Bloom diantaranya perubahan nama dalam taksonomi yang mengambil bentuk menjadi kata kerja pada perubahan urutan taksonomi dimana taksonomi lama terdapat pada urutan akhir berubah menjadi urutan kelima dan sintesis dalam taksonomi lama diganti menjadi mencipta dan perubahan sub kategori.[4] Dalam revisi taksonomi bloom ini ada hal-hal penting yang harus diperhatikan yaitu pengetahuan metakognisi dan table taksonomi serta melihat manfaat dalam belajar dengan merevisi taksonomi ini banyak hal yang harus dilakukan dan akan berdampak juga dalam proses belajar pada seseorang. Dengan mempelajari makna penting dalam taksonomi ini seseorang akan semakin bertambah wawasannya dan meningkatkan pengetahuan tentang hal-hal penting apa saja yang terkandung dalam tingkatan pemahaman belajar setiap individu.

Karya kedua Sujoko di tahun 2016 membahas tentang mama mela menyanyi untuk menghidupkan makna dari pelajaran IPS pada siswa sekolah dasar di dukuh 03 salatiga, karena disana didapatkan adanya permasalahan yaitu pembelajaran masih berpusat pada guru, suasana kelas pasif dan hasil belajar kurang optimal. Dan ada beberapa faktor juga yang menyebabkan rendahnya aktivitas belajar dan hasil belajar siswa adalah metode yang digunakan kurang tepat, media yang digunakan kurang menarik, materi yag sebagaian besar bersifat hafalan, dan siswa malas membaca materi yang padat.maka dari itu perlu adanya sebuah metode yang baru dalam langkah mengajar yang harus dimiliki seorang guru agar dalam proses pembalajaran berlangsung khususnya mata pelajaran IPS tidak terlalu pasif dengan menerapkan beberapa hal yaitu membuat suasana didalam kelas menyenangkan dengan memberi waktu untuk siswa berfikir kritis dalam memahami materi ajar dengan menyampaikan pertanyaan-pertanyaan yang menyangkut materi ajar dan membuat sebuah metode 
bernyanyi ketika menghafal materi ajar strategi seperti ini sangat berguna untuk menumbuhkan semangat belajar anak dan kelas tidak lagi pasif melainkan aktif dan menyenangkan dan siswa pun dapat dengan baik menerima materi ajar.

Sujoko dan Hana S.K mengungkapkan Arti kata dari mama mela menyanyi memiliki kelebihan yaitu mampu memberikan manfaat bagi pengembangan kognitif, afektif, dan psikomotorik siwwa. Selain bersifat menyenangkan, juga bisa membantu daya tarik siswa. Membantu siswa lebih mudah memahami materi yang bersifat hafalan, dan yang tidak kalah penting memberi ruang kepada siswa untuk aktif tanpa dominasi guru sehingga bisa meningkatkan aktivitas dan hasil belajar siswa.[5]

Pada tahun 2017 Sujoko menghasilkan 5 (lima) karya artikel jurnal, dan salah satunya adalah bentuk prosiding satu bab. Karya pertama ini membahas tentang Strategi peningkatan Mutu Sekolah Berdasarkan Analisis Swot Di Sekolah Menengah, Survey terhadap kepuasaan mahasiswa pada kualitas layanan di STT Simpson Ungaran, Model Pengembangan Pelayanan anak, Strategi Peningkatan Profesionalisme Pendidik Pada STT Simpson. Dalam jurnal tersebut Sujoko menekankan tentang perlu dan pentingnya Strategi dalam meningkatkan mutu sekolah berdasarkan analisis swot agar setiap pendidik harus memperhatikan dan ikut bekerja sama dalam mewujdukan sekolah yang mempunyai pendidik atau guru yang professional dan menjalankan perannya menjadi pendidik agama kristen yang memiliki ajaran yang benar dan berkualitas Sujoko.[1] Implikasi bagi pendidik adalah pentingnya mengimplementasikan Pendidikan agama kristen dalam konteks gereja, untuk pendidikan dapat berperan penting juga dalam mengenalkan setiap orang dalam pengenalan akan Kristus melalui dunia pendidikan disekolah-sekolah dalam melihat perkembangan zaman sekarang ini agar tidak hidup dalam paradigma yang salah dalam mencapai atau mengatur strategi dalam dunia pendidikan. Peran para pendidik sangat diperlukan, terutama bagi para Pendidik Kristen dalam melayani atau melihat karakter yang baik bagi jemaat yang dlayani melalui impelementasi pendidikan agama 
kristen dalam konteks gereja untuk mengajarkan tentang firman Tuhan yang dapat berdampak baik bagi setiap orang.

Karya Sujoko pada tahun 2017 tentang Strategi Peningkatan Profesionalisme Pendidik Pada STT Simpson Ungaran Kabupaten Semarang.[6] Dalam karya tulis ini ada banyak bagian penting yang harus di perhatikan mengingat perubahan lingkungan yang sangat cepat dalam bidang teknologi dan ilmu pengetahuan, maka setiap lembaga mulai mempersiapkan sumber daya manusia yang kompoten dan professional agar dapat memberikan kualitas layanan yang prima, bernilai seta mampu menghadapi persaingan yang ada. Dalam konferensi seminar nasional pendidikan agama kristen sangat perlu dilaksanakan pemberian materi seperti ini supaya di sekolah-sekolah yang termasuk kurang sumber daya manusia yang berkualitas akan diberikan solusi yang baik dalam memilih dan memantau para pendidik agama kristen secara khusus yang kompoten dalam bekerja dan mampu memberikan ilmu-ilmu yang sangat bermanfaat dan terpercaya bagi yang didiknya di dalam lingkup sekolah-sekolah.

Strategi seperti ini sangat diperlukan para pendidik STT Simpson dalam meningkatkan kualitas dalam bidangnya khusunya dalam bidang pendidikan agama Kristen, strategi ini sangat baik di ambil sebagai panduan dalam menjadi seorang pendidik yang berkompeten dan bisa diandalkan dalam dunia pendidikan untuk memberikan wawasan yang luas biasa kepada orang-orang yang akan dididik nantinya. Karena pada dunia pendidikan secara khusus dalam mendapatkan caloncalon pendidik yang kompoten dan luar biasa dalam bidangnya, maka harus ada usaha untuk menjadi pendidik yang luar biasa dalam bidang yang di ambil dan bermanfaat luar biasa juga dalam pendidikan terutama pendidikan agama kristen.

Karya Sujoko pada tahun 2017 tentang model pelayanan pengembangan anak, karya ini ditulis untuk memberikan penjelasan tentang model pengembangan pelayanan anak sebagai pelaksanaan amanat agung di abad 21.[7] Karena sangat penting sebagai orang tua maupun pendidik kristen dalam mempelajari berbagai macam model dalam mengembangkan strategi dalam melayani anak, karena pada usia 
anak-anak lah sangat perlu dberikan penjelasan-penjelasan dari makna kebenaran tentang amanat dari Allah yang maha suci, dengan mengajarkan anak salah satunya untuk hormat kepada orang tua dan mengasihi Tuhan dengan sepenuh hati, dari masa anak-anak inilah anak akan mendapatkan pemahaman yang benar dari guru-guru agama kristen secara khusus yang memiliki peran penting selain peran orang tua dirumah membina anak guru juga wajib untuk memberikan pelayanan yang benar dengan anak dan digereja juga harus ada pembinaan pelayanan khusus untuk anak supaya iman mereka kepercayaan mereka kepada Tuhan dari kecil sudah dikembangkan dengan baik setelah dewasa anak akan memiliki perilaku dan sikap yang baik dan cinta Tuhan dalam hidupnya.

Pada tahun 2019, Edi Sujoko kembali menghasilkan 2 (dua) karya artikel ilmiah. Karya pertama membahas tentang Understanding Ki Hajar Dewantara's Educational Philosophy dimana Ki Hajar Dewantara memberikan suatu filosopi tentang pendidikan yang sangat penting dan memiliki makna yang khusus dalam dunia pendidikan. Dalam jurnal tersebut Darmawan, Edi menekankan tentang makna yang terkandung dalam filosopi Ki Hajar Dewantara dalam pendidikan yang harus memiliki makna yang mendasar agar tidak sembarangan dalam memaknai pendidikan dan para pendidik yang memiliki nilai yang tinggi serta dapat menunjukan profesionalitas yang berkualitas sebagai pendidik.[8] Implikasi bagi pendidikan adalah perlunya pendidik yang mempunyai nilai yang tinggi dan professional serta berkualitas dalam sebuah lembaga sekolah supaya dalam mendidik atau mengajarkan sesuai dengan bidangnya dan sesuai dengan keahliannya sebagai pendidik yang berkualitas.

Karya Sujoko dkk tahun 2019, mengungkapkan tentang Implementing Total Quality Management In Christian Lesson dalam bentuk prosiding pada worksop tentang multi disiplin dan aplikasinya pada WMA-3.[9] Materi yang disampaikan pada workshop ini penting sekali untuk dipelajari dengan seksama bagaimana melihat pengertian dan pesan penting dalam multidisiplin berserta penerapan atau aplikasinya sehingga tidak hanya memahami materinya tetapi mampu menerapkan dalam setiap 
aspek. Makna pentingnya juga akan didapatkan ketika mempelajari materi workshop ini dan setiap orang juga akan semakin ditambah pengetahuannya.

Karya Sujoko di tahun 2019 membahas tentang Implementasi PAK Konteks Gereja Di GKII Tandang Semarang yang memberikan penjelasan bahwa pentingnya sebuah pendidikan agama kristen ada dalam konteks atau lingkup gereja karena pendidik juga memiliki peran yang penting dalam mengajarkan dan membawa setiap orang yang dididik mengenal Kristus dan pendidik juga mampu mendewasakan seseorang dalam iman kepada Kristus. Nuh, Darmawan, Sujoko menekankan peran pendidik dalam mejalankan tugasnya yang penting dalam mengajarkan setiap orang mengenal pribadi Kristus.[3] Implikasi bagi pendidikan adalah pentingnya pendidikan bagi anak-anak bukan hanya sebatas pengetahuan yang didapatkan disekolah saja. Akan tetapi pendidikan merupakan sebuah amanah dari Allah bagi setiap pendidik khususnya pendidik agama kristen yang harus mengajarkan anak-anak didiknya atau orang dewasa untuk mengenal Kristus. Supaya guru juga berperan penting dalam membawa setiap orang dan mendewasakan didalam pengenalan akan pribadi Allah itu sendiri.

\section{Grafik Hasil Karya Ilmiah}

Dari hasil analisis terhadap karya tulis Edi Sujoko, maka grafiknya adalah:

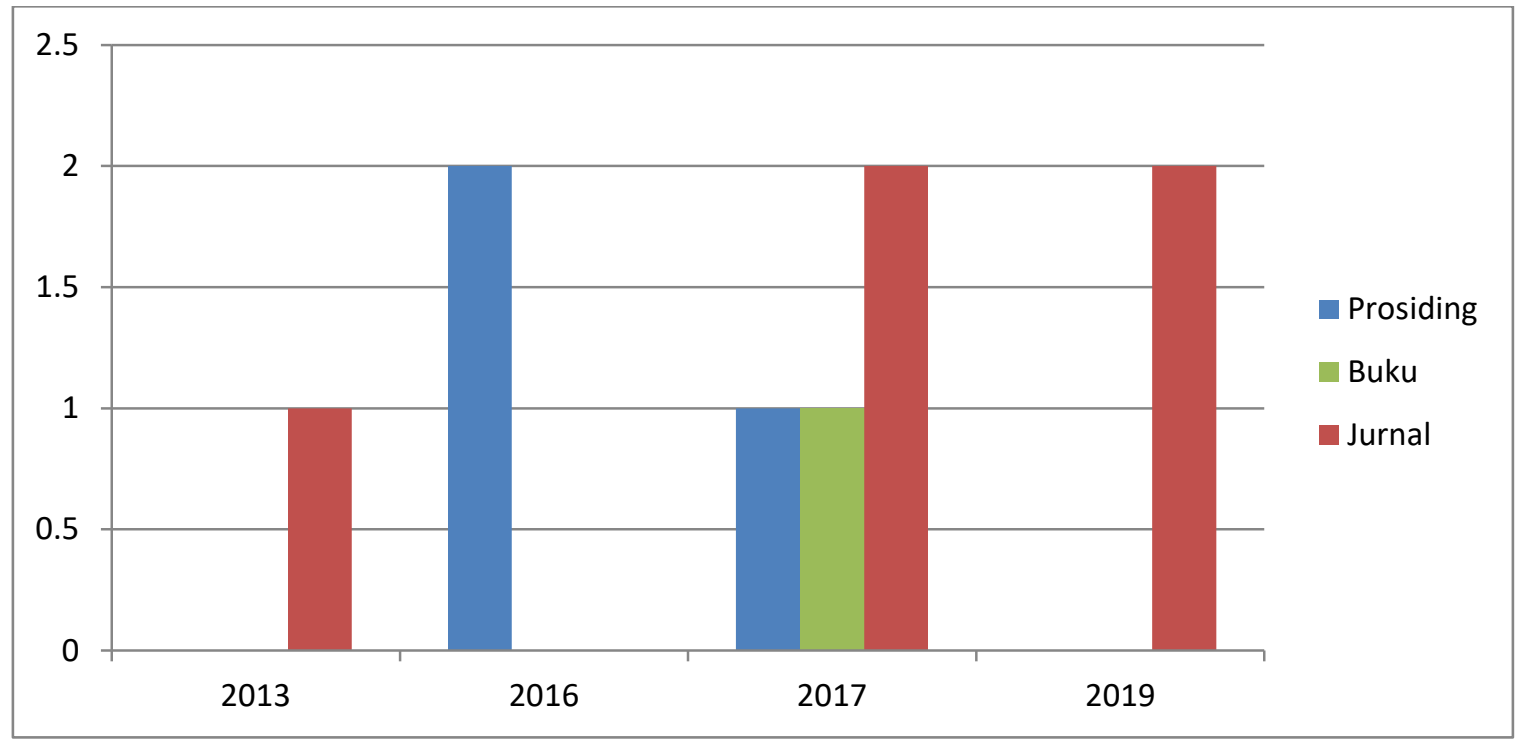


Berdasarkan ulasan jurnal tahun 2013-2017, dapat dikatakan bahwa dosen telah menghasilkan karya sesuai bidangnya tetapi dalam tahun 2019 mengalami penurunan dalam menghasilkan karya tulis ilmiah dan dari hasil grafik menyatakan bahwa karya ilmiah yang dihasilkan mengalami penurunan. Dengan demikian dosen diharuskan untuk berusaha lagi dalam menghasilkan karya ilmiah terbaru untuk mengembangkan diri melalui proses penelitian yang tentunya bagi pendidikan dan kualifikasi sebagai dosen. Berdasarkan hasil wawancara yang sudah dilakukan pada hari Senin, 23 Maret 2020, faktor-faktor penghambat dalam penulisan artikel jurnal yang dianggap terjadi penurunan yaitu: kurangnya kemauan yang kuat dalam menyelesaikan artikel yang sudah direncanakan, dikarenakan kesibukan pekerjaan yang juga mempengaruhi penurunan jumlah artikel.

\section{Daftar Pustaka}

[1] E. Sujoko, "Strategi Peningkatan Mutu Sekolah Berdasarkan Analisis SWOT di Sekolah Menengah Pertama," Kelola: Jurnal Manajemen Pendidikan, vol. 4, no. 1, hlm. 83-96, 2017.

[2] I. P. A. Darmawan dan E. Sujoko, "Survei Terhadap Kepuasan Mahasiswa Pada Kualitas Layanan Di STT Simpson Ungaran, Semarang, Jawa Tengah," Satya Widya, vol. 33, no. 1, hlm. 45-53, 2017.

[3] S. Nuh, I. P. A. Darmawan, dan E. Sujoko, "IMPLEMENTASI PAK KONTEKS GEREJA DI GKII TANDANG, SEMARANG," Pengarah: Jurnal Teologi Kristen, vol. 1, no. 1, hlm. 59-70, 2019.

[4] I. P. A. Darmawan dan E. Sujoko, "Revisi taksonomi pembelajaran benyamin s. bloom," Satya Widya, vol. 29, no. 1, hlm. 30-39, 2013.

[5] H. S. Kristanti dan E. Sujoko, Mama mela Menyanyi Untuk Meningkatkan Aktivitas Belajar Dan Hasil Belajar. Ungaran: Sekolah Tinggi Teologi Simpson, 2016. 
[6] E. Sujoko, "Strategi Peningkatan Mutu Profesionalisme Pendidik Pada STT Simpson Ungaran Kabupaten Semarang," dalam Seminar Nasional Pendidikan Agama Kristen dan call for papers, Ungaran, 2017.

[7] E. Sujoko, "Model Pengembangan Pelayanan Anak," dalam Melaksanakan Amanat Agung di Abad 21, I. P. A. Darmawan, Ed. Ungaran: Sekolah Tinggi Teologi Simpson, 2017.

[8] I. P. A. Darmawan dan E. Sujoko, “Understanding Ki Hadjar Dewantara's educational philosophy," International Journal of Humanities and Innovation (IJHI), vol. 2, no. 3, hlm. 65-68, 2019.

[9] D. T. Putri, I. P. A. Darmawan, dan E. Sujoko, “Implementing Total Quality Management In Christian Lesson," dalam Proceedings of the Third Workshop on Multidisciplinary and Its Applications, WMA-3 2019, 11-14 December 2019, Medan, Indonesia, Medan, 2020. 